Caderno Seminal Digital

Â

\title{
A IMPORTÂNCIA DAS FICHAS LEXICOGRÁFICO-TOPONÍMICAS NA ELABORAÇÃO DO ATLAS TOPONÍMICO DO ESTADO DE MATO GROSSO
}

THE IMPORTANCE OF THE LEXICOGRAPHIC-TOPONYMIC FILES IN THE ELABORATION OF THE TOPONYMIC ATLAS OF MATO GROSSO STATE

Maria Aparecida de Carvalho (USP)

Resumo: As pesquisas toponímicas realizadas nas mesorregiões: Centro-Sul Mato-grossense e Sudeste Mato-grossense, constituídas por 4.581 topônimos, estabeleceram o início da elaboração do Atlas Toponímico do Estado de Mato Grosso. Os topônimos encontram-se registrados em 39 municípios que compõem 08 microrregiões matogrossenses: Alto Araguaia, Alto Pantanal, Alto Paraguai, Cuiabá, Primavera do Leste, Rondonópolis Rosário Oeste e Tesouro. O total de topônimos pesquisados evidencia o nível de abrangência da pesquisa. Os levantamentos dos sintagmas toponímicos foram efetuados em mapas e em cartas topográficas, escala 1:100.000. Elaboramos as fichas lexicográfico-toponímicas para montar o banco de dados e este, por sua característica de conservador de dados, possibilita fácil acesso às informações necessárias para subsidiar a pesquisa a ser efetuada. As fichas lexicográficotoponímicas têm características individuais e, por isso, contêm informações mais detalhadas e específicas de cada acidente físico e de cada acidente antrópico.

Palavras-chave: Topônimo. Sintagma toponímico. Ficha lexicográfico-toponímica.

Abstract: The toponymic researches carried out in the mesoregions: Center-South and Southeast of Mato Grosso, formed by 4.581

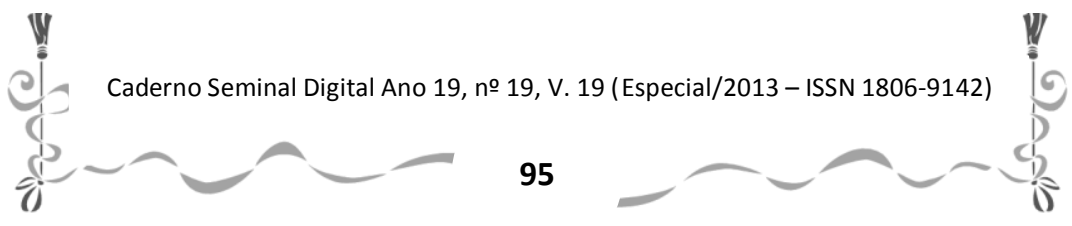


toponyms, have established the onset of the elaboration of the Toponymic Atlas in Mato Grosso state. The toponyms are registered in 39 municipalities that are part of the 08 mato-grossense microregions: Alto Araguaia, Alto Pantanal, Alto Paraguai, Cuiabá, Primavera do Leste, Rondonópolis, Rosário Oeste and Tesouro. The total of toponyms researched highlights the level of coverage of this research. The surveys of the toponymic syntagmas were performed in maps and in topographic charts, scale 1:100.000. We elaborated the lexicographic-toponymic files to create data bank which for its characteristic of data preserver, enables easy access to the necessary information to finance the research to be done. The lexicographic-toponymic files have individual characteristics and, because of this, contain more detailed and specific information of each physical accident and of each antropic accident.

Keywords: Toponym. Toponymic Syntagma. Lexicographictoponymic file.

\section{INTRODUÇÃO}

Pretendemos compartilhar um dos modelos das fichas lexicográfico-toponímicas que utilizamos para especificar as principais características dos topônimos registrados nas mesorregiões: Centro-Sul Mato-grossense e Sudeste Matogrossense.

Conservamos, ao iniciar a pesquisa do doutorado, os mesmos modelos das fichas lexicográfico-toponímicas que foram utilizadas na pesquisa do mestrado, com o objetivo de ampliar o banco de dados e também de manter a

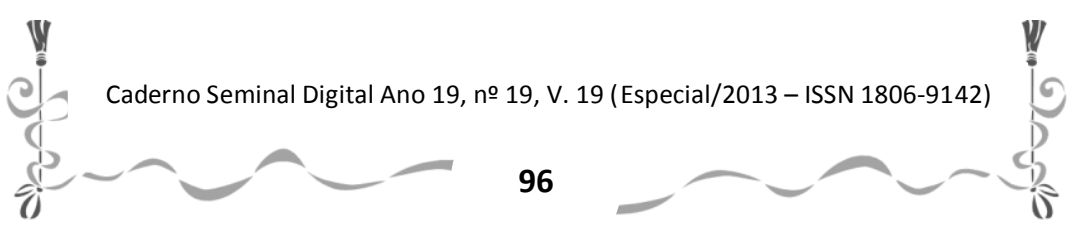


Caderno Seminal Digital

站

padronização das análises porque consideramos que estas fichas contêm informações que subsidiam a pesquisa toponímica.

Os levantamentos dos sintagmas toponímicos foram efetuados nas cartas topográficas elaboradas pela Diretoria de Serviço Geográfico (DSG) do Ministério do Exército e pelo Instituto Brasileiro de Geografia e Estatística (IBGE), e também, nos mapas elaborados pela Secretaria de Estado de Planejamento e Coordenação Geral (SEPLAN - MT) e pela Fundação de Pesquisa Cândido Rondon (FCR).

\section{ASPECTOS METODOLÓGICOS DA PESQUISA TOPONÍMICA}

O estudo dos topônimos de uma determinada região pode constituir, ao mesmo tempo, um registro científico, um resgate e, até mesmo, a preservação da cultura e da memória dos povos que habitaram e que habitam um determinado lugar. No Brasil, existe atualmente um progressivo aumento nas pesquisas toponímicas e esses estudos demonstram a importância da disciplina no contexto acadêmico.

Acreditamos que, as pesquisas pioneiras já realizadas por vários pesquisadores no exterior e em vários estados brasileiros, artigos publicados nesta área por Dauzat, Rostaing, Backheuser, Drumond e Dick, no que concerne às análises dos topônimos, deram suportes necessários às pesquisas toponímicas efetuadas em cada um dos 39 (trinta e nove) municípios mato-grossenses já pesquisados. As pesquisas e os

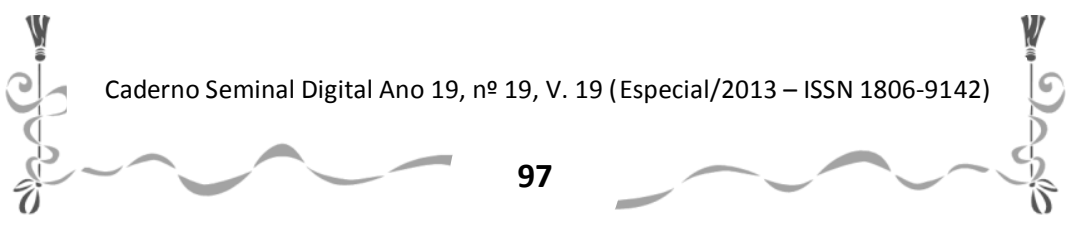


Caderno Seminal Digital

住

artigos publicados por Dick, que se expandiram a partir da publicação de sua tese de doutoramento em 1980 e que tiveram prosseguimento nos anos subsequentes, estabeleceram, no Brasil, um marco firme e divisor nesta área. Pode-se considerar que são trabalhos que serviram e servem de base para estudos e pesquisas realizados em vários estados do Brasil.

\section{LEVANTAMENTO E ORGANIZAÇÃO DOS DADOS}

Os levantamentos dos topônimos foram realizados em mapas municipais para alguns municípios e, para os outros, foram em cartas topográficas, todos em escala 1:100.000. Depois efetuamos verificações, nos mapas, com relação aos topônimos para nos certificarmos quanto à grafia, mas também, pelo fato de um mesmo acidente físico encontrar-se registrado em mais de um município. Isto ocorreu não só em relação a rios, que em geral, são acidentes físicos com maior extensão, mas também, em relação a outros como: serras, ribeirões e córregos.

Também nas cartas topográficas foram necessárias verificações, porém, desta vez, confrontamos as cartas topográficas com os mapas dos municípios, muito embora os mapas estivessem em escala maior à das cartas topográficas. Este último procedimento visava reconferir os limites municipais e marcar os acidentes antrópicos de cada município nas cartas topográficas.

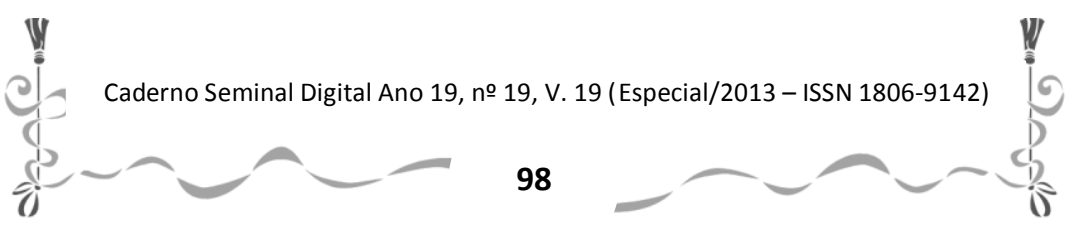


Caderno Seminal Digital

Antes de iniciar o levantamento dos sintagmas toponímicos (termo genérico + topônimo), propriamente ditos, quadriculamos os mapas. Estas quadrículas foram marcadas na horizontal por números (de $1 \ldots \mathrm{n}$ ) e na vertical pelas letras do alfabeto brasileiro. Estas, em geral, nos mapas ficaram com um tamanho médio de $3,5 \mathrm{~cm}^{2}$. Em alguns mapas houve repetição de letras do alfabeto, devido ao tamanho maior desses mapas. Tomamos essas precauções para que tanto o acidente quanto o topônimo fossem mais facilmente localizados nos respectivos mapas. No que se refere às cartas topográficas, consideramos as quadrículas existentes que foram marcadas da forma acima descrita, cabendo ainda registrar que a cada carta topográfica está designado um número. O número da carta topográfica, em conjunto com as letras e os números das quadrículas, possibilita pronta identificação dos topônimos.

É preciso também destacar que, com os levantamentos realizados nas cartas topográficas, é possível saber quantos e quais topônimos existem por carta topográfica em cada município. Esse procedimento exigiu um tempo maior para a realização do levantamento cartográfico, mas consideramos que possibilitou maior confiabilidade à pesquisa. Outro item preponderante foi o fato de que para trabalhar com a área total da maioria dos municípios pesquisados é necessário reunir várias cartas para cobrir a área municipal total. A esse processo dá-se o nome de articulação de cartas topográficas.

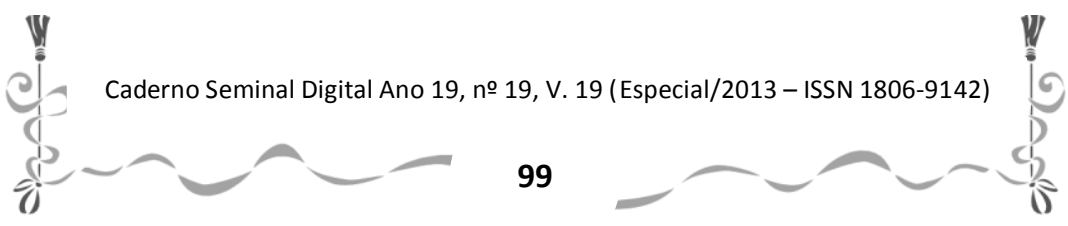


Caderno Seminal Digital

a

O número de cartas varia de acordo com a extensão territorial do município.

Essas cartas topográficas não trazem, como já mencionamos, os limites municipais demarcados e, além disso, devido aos muitos desmembramentos de áreas municipais para criar novos municípios, foi preciso atualizar os limites dos municípios que fizeram cessão de áreas, portanto, houve necessidade de articulá-las porque algumas cartas contêm áreas de mais de um município. Nesse caso, os limites são traçados a mão, a fim de que os topônimos sejam coletados dentro das áreas limítrofes de cada unidade administrativa municipal e não ocorra a inserção de topônimos de um município em outro.

Após o levantamento dos topônimos, para cada município, foi elaborada uma relação para os acidentes físicos e outra para os antrópicos. A relação contém quatro colunas. Vale ainda ressaltar que, buscando possibilitar a localização precisa de cada topônimo, seja nos mapas ou nas cartas topográficas, ainda foram inseridas notas entre parênteses, na terceira coluna da tabela, logo após cada topônimo. Essas notas adicionais são letra(s) e número(s) de quadrícula(s) quando registrados nos mapas e números de carta topográfica, letra(s) e número(s) de quadrícula(s), quando coletados nas cartas topográficas.

Acreditamos que com este sistema seja possível alcançar um importante objetivo, que é estabelecer uma visão

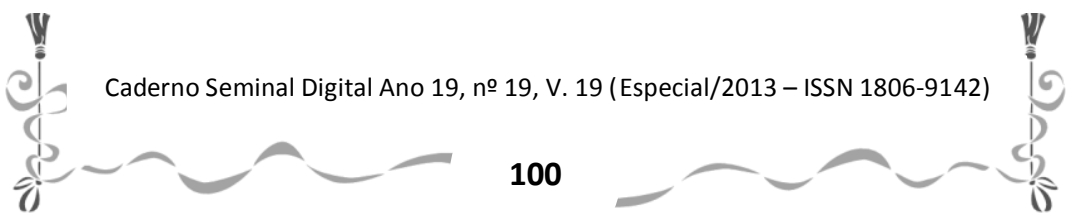


toponímica global de cada município, por meio dessas relações de topônimos; também é possível saber quais os tipos de acidentes e quantos existem; a quantidade de topônimos por municípios e, se necessário, saber quantos e quais topônimos por tipo de acidente, quais as taxionomias existentes, quais as taxionomias predominantes por município, por microrregião e por mesorregião.

\section{COMPOSIÇÃO DAS MESORREGIÕES MATO-GROSSENSES PESQUISADAS}

Os levantamentos dos sintagmas toponímicos, quando da dissertação de mestrado, foram realizados em 10 (dez) mapas e em 56 (cinquenta e seis) cartas topográficas que se referem aos 17 (dezessete) municípios que compõem a mesorregião Centro-Sul Mato-grossense.

\section{MESORREGIÃO CENTRO-SUL MATO-GROSSENSE}

\begin{tabular}{|c|c|c|c|}
\hline \multicolumn{4}{|l|}{ Microrregiões } \\
\hline Alto Pantanal & Alto Paraguai & Cuiabá & Rosário Oeste \\
\hline $\begin{array}{ll}\text { Barão } & \text { de } \\
\text { Melgaço } & \end{array}$ & Alto Paraguai & $\begin{array}{ll}\text { Chapada } & \text { dos } \\
\text { Guimarães } & \end{array}$ & Acorizal \\
\hline Cáceres & Arenápolis & Cuiabá & Jangada \\
\hline Curvelândia & Nortelândia & $\begin{array}{l}\text { Nossa Senhora do } \\
\text { Livramento }\end{array}$ & Rosário Oeste \\
\hline Poconé & $\begin{array}{l}\text { Nova } \\
\text { Marilândia }\end{array}$ & $\begin{array}{l}\text { Santo Antônio de } \\
\text { Leverger }\end{array}$ & \\
\hline & Santo Afonso & Várzea Grande & \\
\hline
\end{tabular}

Fonte: IBGE, 2005.

Caderno Seminal Digital Ano 19, no 19, V. 19 (Especial/2013 - ISSN 1806-9142) 
Caderno Seminal Digital

A pesquisa toponímica que desenvolvemos, para a tese de doutorado, contemplou 22 (vinte e dois) municípios da mesorregião Sudeste Mato-grossense. Os levantamentos dos sintagmas toponímicos foram realizados em 42 (quarenta e duas) cartas topográficas e 17 (dezessete) mapas.

\section{MESORREGIÃO SUDESTE MATO-GROSSENSE}

\begin{tabular}{|c|c|c|c|}
\hline \multicolumn{4}{|c|}{ Microrregiões } \\
\hline $\begin{array}{l}\text { Alto } \\
\text { Araguaia }\end{array}$ & Primavera do Leste & Rondonópolis & Tesouro \\
\hline $\begin{array}{l}\text { Alto } \\
\text { Araguaia }\end{array}$ & Campo Verde & Dom Aquino & Araguainha \\
\hline Alto Garças & Primavera do Leste & Itiquira & General Carneiro \\
\hline \multirow[t]{7}{*}{ Alto Taquari } & & Jaciara & Guiratinga \\
\hline & & Juscimeira & $\begin{array}{ll}\text { Pontal do } \\
\text { Araguaia }\end{array}$ \\
\hline & & Pedra Preta & Ponte Branca \\
\hline & & Rondonópolis & Poxoréu \\
\hline & & São José do Povo & Ribeirãozinho \\
\hline & & $\begin{array}{lll}\text { São } & \text { Pedro } & \text { da } \\
\text { Cipa } & & \end{array}$ & Tesouro \\
\hline & & & Torixoréu \\
\hline
\end{tabular}

Fonte: IBGE. 2010.

Nas duas pesquisas, antes de iniciarmos a análise dos dados, optamos por adotar o procedimento metodológico de preencher a ficha referente a cada sintagma toponímico de cada um dos municípios, sobretudo, porque ela contém os

Caderno Seminal Digital Ano 19, no 19, V. 19 (Especial/2013 - ISSN 1806-9142) 
Caderno Seminal Digital

elementos necessários que, como já dissemos, possibilitam observações mais aprofundadas. Desse modo e a partir desse ponto, foi possível desenvolver a análise dos topônimos por município, também por microrregião e, consequentemente, por mesorregião. As fichas estão catalogadas por municípios.

\section{FICHA LEXICOGRÁFICO-TOPONÍMICA}

A etapa final da busca e organização dos dados foi o preenchimento da ficha lexicográfico-toponímica para cada topônimo encontrado. Elaboramos três tipos de fichas: um para os municípios, um para os acidentes físicos e um terceiro tipo de ficha para os demais acidentes antrópicos. Destacamos que é elaborada, quando ocorre uma dupla ou até mesmo, tripla nomeação, ou seja, um mesmo acidente recebe dois ou mais nomes, uma ficha lexicográfico-toponímica para cada topônimo do acidente. Cada uma delas com a classificação taxionômica correspondente devidamente computada no total de topônimos do município correspondente. Foram utilizados três modelos de fichas.

A primeira delas foi a ficha lexicográfico-toponímica de município para registrar informações relativas ao município / cidade. Esse tipo de ficha foi o que apresentou menor quantidade nas duas pesquisas, ou seja, foram 39 (trinta e nove) fichas ao todo.

O segundo modelo de ficha lexicográfico-toponímica foi o de acidente antrópico para registrar informações

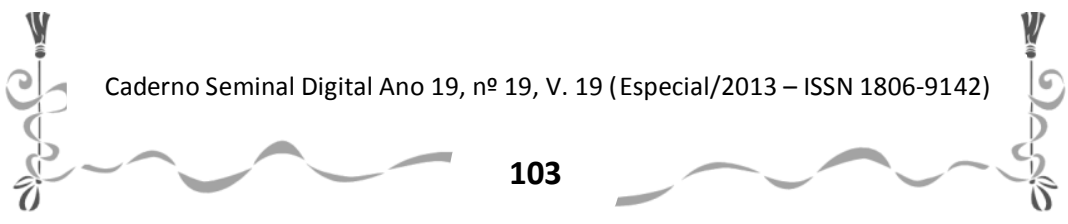


Caderno Seminal Digital

î.

relativas a distritos, localidades, povoados, terras indígenas, etc. Esses acidentes antrópicos foram considerados, quer tenham sido criados por lei ou não, desde que constassem nos mapas ou nas cartas topográficas pesquisadas. Este segundo modelo já apresentou um montante mais expressivo. Foram 180 (cento e oitenta) fichas.

O terceiro modelo de ficha lexicográfico-toponímica foi o de acidente físico para registrar as informações pertinentes aos acidentes físicos existentes em cada um dos municípios pesquisados. O somatório foi 4.362 (quatro mil, trezentos e sessenta e duas) fichas.

São, ao todo, 4.581 (quatro mil, quinhentos e oitenta e uma) fichas. Sendo que 2.233 (duas mil, duzentas e trinta e três) fazem parte do acervo da dissertação e 2.348 (duas mil, trezentas e quarenta e oito) do doutorado.

As fichas, em geral, são bastante semelhantes. A ficha lexicográfico-toponímica de acidente antrópico (distritos, vilas, povoados, etc.), é praticamente igual à ficha lexicográficotoponímica de município. Apenas diferem quanto ao campo 19. Nesta o campo 19 se refere aos limites municipais e tem, portanto, um campo a mais que as outras, ou seja, possui vinte e seis campos.

A ficha lexicográfico-toponímica de acidente físico (baía, córrego, morro, etc.), é praticamente igual à ficha lexicográfico-toponímica de acidente antrópico. Possuem

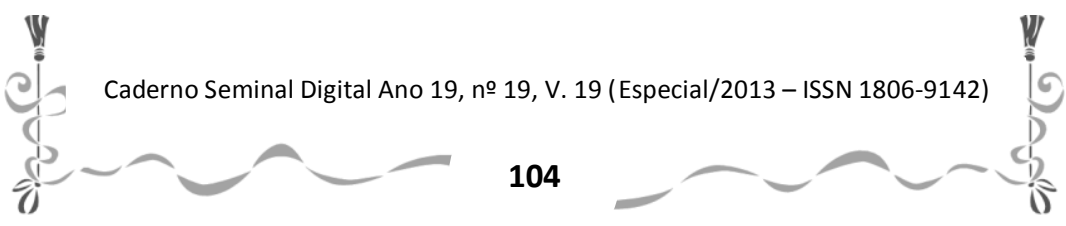


Caderno Seminal Digital

î.

vinte e cinco campos. A única diferença entre ambas é que no campo 06 de uma constam os vocábulos: acidente humano e na outra constam os vocábulos: acidente físico.

Apresentamos a ficha lexicográfico-toponímica, neste caso específico, a ficha (vazia) para um acidente físico.

\section{CAMPOS DA FICHA LEXICOGRÁFICO-TOPONÍMICA DE ACIDENTE FÍSICO}

Os campos que compõem a ficha lexicográficotoponímica de acidente físico são os seguintes:

. Campo 01 - NUMERAÇÃO - deste campo consta o número sequencial do topônimo, conforme se encontra na relação de topônimos do município.

. Campo 02 - UNIDADE DA FEDERAÇ̃̃O - neste campo registra-se a Unidade Federativa, onde se encontra 0 topônimo pesquisado, com sua respectiva sigla.

. Campo 03 - MESORREGIÃO - este campo contém o nome da mesorregião na qual o acidente está inserido.

. Campo 04 - MICRORREGIÃO - deste campo consta o nome de uma das microrregiões que compõe a mesorregião e na qual se registra o topônimo.

. Campo 05 - MUNICÍPIO - deste campo consta o nome do município onde se localiza o topônimo.

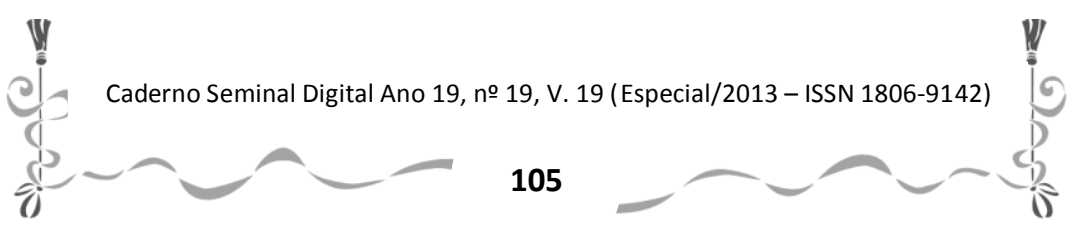


Caderno Seminal Digital

. Campo 06 - ACIDENTE FÍSICO OU ACIDENTE HUMANO

- deste campo consta o termo genérico (baía, córrego, distrito, vila, etc.) do sintagma toponímico.

. Campo 07 - TOPÔNIMO - deste campo consta a denominação do acidente físico ou do acidente humano.

. Campo 08 - VARIANTE GRÁFICA - deste campo consta (se houver) a forma variante do vocábulo que dá nome ao acidente físico ou acidente humano.

. Campo 09 - TAXIONOMIA - neste campo registra-se a qual campo semântico pertence o topônimo.

. Campo 10 - ESTRUTURA DO TOPÔNIMO - deste campo consta qual é a estrutura (simples, híbrida ou composta) do topônimo.

. Campo 11 - ESTRUTURA MORFOLÓGICA - deste campo consta a qual classe de palavras pertence o topônimo e, se apresentar estrutura composta ou derivação, especificase como está formado.

. Campo 12 - ETIMOLOGIA TUPI / BORORO / AFRICANA - registra(m)-se neste campo a(s) acepção(ões) selecionada(s) da unidade lexical que dá nome ao acidente físico ou ao acidente humano e a especificação a qual grupo linguístico ela(s) pertence $(\mathrm{m})$.

. Campo 13 - FONTE - deste campo consta $(m)$ a fonte da(s) acepção(ões) selecionada(s).

Caderno Seminal Digital Ano 19, no 19, V. 19 (Especial/2013 - ISSN 1806-9142)
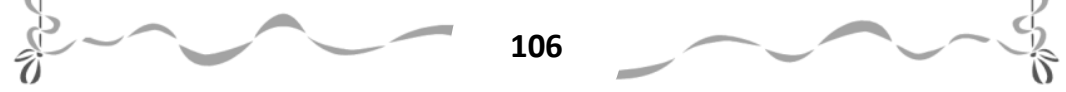
Caderno Seminal Digital

. Campo 14 - ENTRADA LEXICAL - registra(m)-se neste campo a(s) acepção(ões) que mais se adequar(em) à definição do topônimo, quando retirada(s) de dicionário de língua geral.

. Campo 15 - FONTE - deste campo consta a fonte (nome do dicionário) da(s) acepção(ões) selecionada(s).

. Campo 16 - INFORMAÇÕES ENCICLOPÉDICAS - neste campo registra(m)-se a(s) acepção(ões) da unidade lexical, quando essa(s) acepção(ões) não constar(em) em dicionário(s) de língua geral, dicionário(s) tupi(s), enciclopédia bororo ou vocabulário(s) de língua(s) indígena(s).

- Campo 17 - FONTE - deste campo consta a fonte pesquisada (dicionário de nomes, enciclopédias, etc.). Para esta pesquisa, no caso de nomes de pessoas, deu-se preferência as definições encontradas no dicionário de $M$. Güérios. Registra-se, para nomes de entidades cristãs ou pagãs, informação contida em livro e/ou enciclopédia. Para os nomes de santas e de santos foi considerado o livro de Sgarbossa \& Giovannini.

. Campo 18 - CONTEXTO - neste campo registra-se a acepção do topônimo, quando esta não constar em uma das fontes já citadas e tiver sido pesquisada na internet ou colhida em pesquisa de campo.

- Campo 19 - OBSERVAÇÕES GERAIS - neste campo relacionam-se informações consideradas relevantes para situar o acidente físico ou o acidente humano.

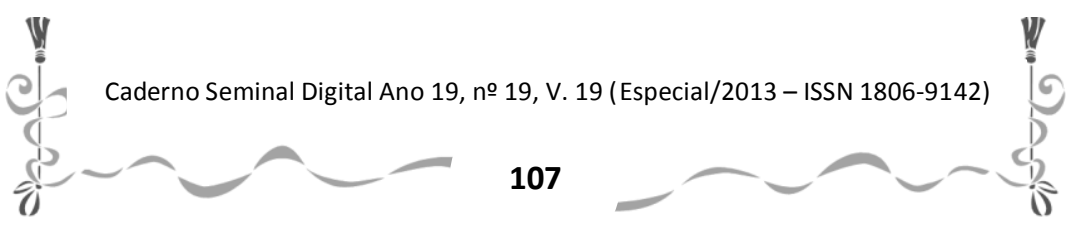


Caderno Seminal Digital

. Campo 20 - ÓRGÂO EXPEDIDOR - deste campo consta o nome do órgão que elaborou o mapa ou a carta topográfica.

- Campo 21 - DATA DO MAPA OU DA CARTA TOPOGRÁFICA - deste campo consta o ano em que o mapa ou a carta topográfica foi elaborado(a).

- Campo 22 - ESCALA DO MAPA OU DA CARTA TOPOGRÁFICA - deste campo consta a escala em que o mapa ou a carta topográfica foi elaborado(a).

. Campo 23 - PESQUISADORA - deste campo consta o nome da pesquisadora que elaborou e preencheu a ficha.

. Campo 24 - REVISORA - deste campo consta o nome da pesquisadora que revisou a ficha.

. Campo 25 - DATA E LOCAL DA COLETA - neste campo registra-se a cidade e a data (mês e ano) do preenchimento da ficha.

\section{CONSIDERAÇÕES FINAIS}

Podemos asseverar que a delimitação prévia do corpus de cada uma das pesquisas foi de primordial importância para um bom desenvolvimento do trabalho. Esse fator possibilitou sequenciar as etapas de coleta, de armazenamento por meio de fichas e de agrupamentos dos topônimos em taxionomias e, em uma etapa subsequente, realizar a pesquisa lexicográfica. O somatório dos topônimos que estão registrados nos mapas e nas cartas topográficas dos 39 (trinta

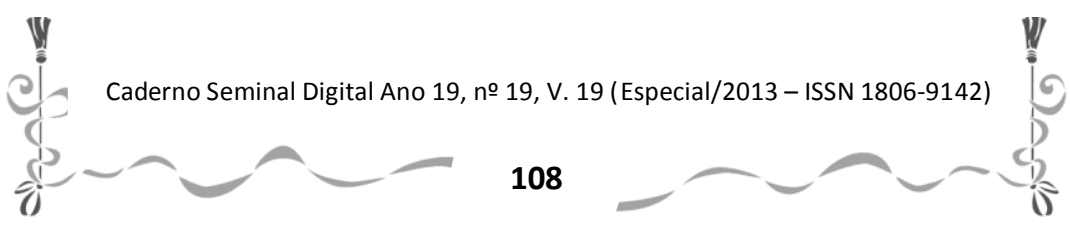


Caderno Seminal Digital

位

e nove) municípios que compõem as duas mesorregiões matogrossense pesquisadas é expressivo e, por isso, demandou criterioso levantamento dos sintagmas toponímicos para que não houvesse necessidade de retornos consecutivos à base de dados, esse fator propiciou conferências reiteradas e atrasos na pesquisa.

Queremos, para concluir, reiterar uma vez mais que consideramos a ficha lexicográfico-toponímica muito importante para desenvolver uma pesquisa toponímica e para montar o banco de dados ao elaborar um Atlas Toponímico de uma microrregião, de uma mesorregião ou de um estado.

Destacamos ainda que quando ocorreu dupla, ou até mesmo, tripla nomeação foi elaborada uma ficha lexicográfico-toponímica para cada topônimo do acidente, com a respectiva classificação taxionômica que foi, devidamente, computada no total de topônimos do município correspondente.

\section{REFERÊNCIAS BIBLIOGRÁFICAS}

BARBOSA, Maria Aparecida. Língua e discurso: contribuição aos estudos semântico-sintáxicos. 4. ed. São Paulo: Plêiade, 1996.

A estruturação do léxico e a organização do conhecimento. v. 22, no 4. Porto Alegre : Letras de Hoje. PUC-RS. 1987, p. 81-96.

BECHARA, Evanildo. Moderna Gramática Portuguesa. 37. ed. rev. e ampl. 14a reimpr. Rio de Janeiro: Lucerna, 2004.

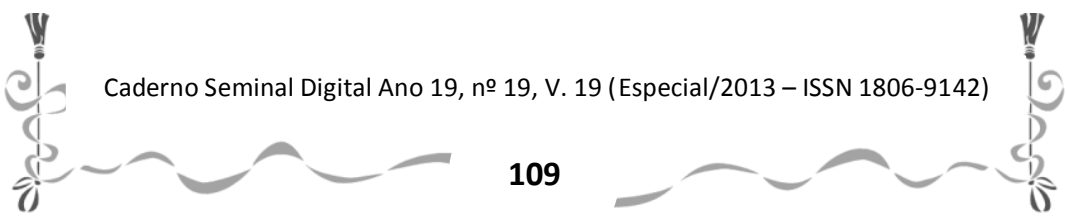


Caderno Seminal Digital

DE CARVALHO, Maria Aparecida. Toponímia da Mesorregião CentroSul Mato-grossense - Contribuições para o Atlas Toponímico do Estado de Mato Grosso. 2005. Dissertação (Mestrado em Linguística) - Faculdade de Filosofia, Letras e Ciências Humanas, Universidade de São Paulo, São Paulo, 2005.

. Contribuições para o Atlas Toponímico do Estado de Mato Grosso - Mesorregião Sudeste Mato-Grossense. 2010. Tese de Doutorado - Faculdade de Filosofia, Letras e Ciências Humanas, Universidade de São Paulo, São Paulo, 2010.

DICK, Maria Vicentina de Paula do Amaral. Atlas Toponímico do Brasil. Estudo de Caso: o Projeto ATESP. In: Acta Semiótica et Lingvistica. v. 6, São Paulo : SBPL e Plêiade, 1996. p. 27-44.

- Toponímia e Antroponímia no Brasil - Coletânea de estudos. 3. ed. São Paulo: FFLCH/USP, 1992.

HOUAISS, Antônio. VILLAR, Mauro de Salles. Dicionário Houaiss da Língua Portuguesa. Rio de Janeiro: Objetiva, 2001.

SACCONI, L. A. Nossa Gramática - Teoria 15. ed. São Paulo: Atual, 1992.

Caderno Seminal Digital Ano 19, no 19, V. 19 (Especial/2013 - ISSN 1806-9142)

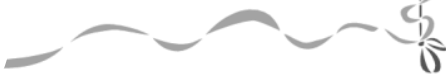

